\title{
Penerapan Diagnosing Organisasi Melalui Intervensi Technostruktural: Studi Literatur
}

\author{
Marjanis*, Hendri Yazid, Rusdinal, Nurhizrah Gistituati \\ Ilmu Pendidikan, Universitas Negeri Padang \\ Jl. Prof. Dr. Hamka Air Tawar Barat Kota Padang \\ *Correspondence email: marjanismarjanis@gmail.com, hendriyazid75@gmail.com, \\ rusdinal@fip.unp.ac.id, gistituatinurhizrah@gmail.com
}

\begin{abstract}
Abstrak. Diagnosa organisasi merupakan salah satu komponen utama dalam melakukan perencanaan perubahan. Diagnosa organisasi merupakan hal yang fundamental bagi pengembangan sekolah. Penelitian ini dimaksudkan untuk menganalisis kontribusi teknologi informasi dan dampaknya terhadap kinerja menejerial organisasi di sekolah. Hal ini dapat ditinjau dari diagnosis organisasi melalui intervensi technostruktural, karena terkait dengan design organisasi, karyawan/pegawai, dan design kerja. Metode intervensi technostruktural fokus pada pengembangan struktur dan desain organisasi serta infrasturktur organisasi. Metode ini akan menghasilkan output peningkatan perhatian pada produktifitas dan efektivitas organisasi di sekolah, seperti kualitas budaya kerja serta metode untuk merancang seluruh komponen yang ada disekolah. Sekolah perlu mengetahui dan berupaya untuk memenuhi sesuai indikator atau kriteria yang ada agar menjadi organisasi yang berkembang dan berintegritas tinggi.
\end{abstract}

Kata Kunci: Penerapan Diagnosing Organisasi; Intervensi Technostruktural

Abstract. Organizational diagnosis is one of the main components in planning change. Organizational diagnosis is fundamental to school development. This can be seen from the organization's diagnosis through technostructural intervention, because it is related to organizational design, employees/employees, and work design. Technostructural intervention method focuses on changes in organizational structure and design, so it tends to be more focused on organizational infrastructure aspects. This method will produce the output of increasing attention to productivity and organizational effectiveness in schools, such as the quality of work culture and methods for designing all components in schools. Schools need to know and strive to meet existing indicators or criteria in order to become a growing organization with high integrity.

Keywords: Application of Organizational Diagnostics; Technostructural Interventions

\section{PENDAHULUAN}

Organisasi merupakan suatu wadah untuk bekerja sama dan berinteraksi secara sistematis, terencana, terstruktur dan terukur. Organisasi dipandang memiliki sifat yang dinamis, karena adanya interaksi secara terus menerus dalam suatu kelompok. Konsekuensi dari itu adalah organisasi berfungsi untuk merespons hubungan interaksional dengan lingkungannya (Roland et al, 2013).

Dalam suatu pengembangan organisasi indentik dengan perubahan. Menurut Robbins dan Timothy (2008), pengembangan organisasi adalah upaya terencana, seluruh organisasi, yang dikelola untuk meningkatkan efektivitas organisasi itu sendiri.

Agar suatu perubahan efektif dan terencana, maka diperlukan diagnosis organisasi. Diagnosis organisasi merupakan salah satu komponen utama dalam melakukan perencanaan perubahan. Hasil diagnosa yang efektif menyediakan pengetahuan yang sistematis bagi organisasi untuk mendesain intervensi yang sesuai (HR Intelligence Report, 2008).

Perencanaan perubahan suatu organisasi bertujuan untuk meningkatkan keefektifan kerja organisasi itu sendiri. Dalam prakteknya mendiagnosis suatu organisasi menggunakan teknik intervensi berencana terhadap proses dalam organisasi dengan memanfaatkan teori-teori perilaku organisasi (Gesimba, 2014). Salah satu intervensi pengembangan organisasi yang dapat dilakukan oleh manajer atau konsultan atau anggota dengan sasaran individu, kelompok, dan organisasi dalah melalui technostruktural intervensi.

Intervensi technostruktural juga dapat diterapkan di lingkungan kerja seperti sekolah. Sekolah adalah tempat untuk berinteraksi dan bersosialisasinya sejumlah orang sehingga akan terbentuk sistem organisasi yang baik (Munandar, 2014). Sistem organisasi sekolah yaitu sistem organisasi terbuka di seluruh elemen yang ada di sekolah. Setiap elemen harus saling mengadakan hubungan timbal balik dengan lingkungannya dan bekerja sama serta merancang secara bersama tentang kemajuan sekolah baik dari segi Sumber Daya Manusianya, maupun tentang pengembangan organisasi dengan menggunakan pendekatan teknologi dan struktural dalam prosesnya.

Kepala sekolah sebagai pimpinan dalam sistem organisasi di sekolah harus slalu berusaha melakukan perbaikan sistem pendidikan untuk meningkatkan mutu dan kualitas pendidikan. Kepala sekolah sebagai leader lembagaan pendidikan harus mampu memahami keberadaan sekolah sebagai organisasi yang kompleks 
serta mampu melaksanakan peranan dan tanggung jawab dalam memajukan sekolah yang dipimpinnya. Kepala sekolah merupakan orang yang paling bertanggung jawab atas keberhasilan sekolah tersebut, karena pengambilan keputusan dan kebijakan yang berkualitas sangat dibutuhkan dalam pengembangan sebuah sekolah (Usman, 2008). Kepala sekolah diharapkan mampu mengatur semua potensi sekolah agar dapat berfungsi secara optimal. Maka dari itu, kepala sekolah harus bijak memfasilitasi proses belajar mengajar serta bijak dalam mengefektivitaskan organisasi dan pengembangan sumber daya manusia dengan berfokus pada teknologi dan struktur organisasi yang ada.

\section{METODE}

Penelitian ini menggunakan pendekatan kualitatif dalam bentuk kepustakaan (Cresweel, 2015). Sumber data penelitian yaitu literatur yang bersumber dari buku, jurnal dan sumber lainnnya. Sasaran pada penelitian ini adalah Kepala sekolah dalam penerapan diagnosa organisasi dan intervensi technostruktural di sekolah yang dipimpinnya. Teknik pengumpulan data dilakukan dengan mencari referensi terkait, baik secara wawancara, maupun observasi. Setelah mencari dari berbagai sumber selanjutnya menyimpulkan dari seluruh referensi yang sudah didapatkan, kemudian mengembangkannya dalam bentuk pengetahuan dan wawasan baru dan mengutip informasi para ahli dari berbagai sumber seperti buku dan jurnal lainnya lalu menuliskannya dalam jurnal ini. Analisis data dilakukan dengan analisis isi (Moleong, 2017).

\section{PEMBAHASAN}

Di era globalisasi saat ini, dunia pendidikan diharuskan untuk meningkatkan kualitas pendidikan yang baik dalam proses pembelajaran (Boyinbode \& Ainyede, 2008). Keberhasilan dalam sebuah pembelajaran tidak hanya terfokus pada tugas dan tanggung jawab seorang guru, melainkan juga terhadap pada bagaimana komitmen dan peran seluruh komponen di sekolah, seperti struktur organisasi di madrasah salah satunya adalah kepala sekolah.

Kepala sekolah sebagai pimpinan di sekolah harus mempunyai sebuah kebijakan yang akan dijalankan oleh seluruh struktur yang ada di sekolah. Kepala sekolah harus mempunyai kemampuan untuk menginspirasi kepercayaan dan mendorong semua masyarakat sekolah untuk mencapai tujuan bersama. Kepala sekolah fokus untuk mengkoordinasikan tim dan mengembangkan kualitas kinerja pegawai, membangun semangat dan motivasi tim dengan cara melakukan pembinaan yang konstruktif hubungan seluruh elemen sekolah (Abdullah et al, 2018).

Budaya organisasi di madrasah merupakan hal fundamental untuk mencapai tujuan pembelajaran yang ingin dicapai sesuai dengan kebijakan kepala sekolah. Kepemimpinan kepala sekolah dilihat dari prestasi sekolah. Aspirasi kepemimpinan didefinisikan sebagai kepentingan pribadi untuk mencapai tujuan berdasarkan aspek psikologis spesifik organisasi (Rahmi, 2014). Memahami factor-faktor yang dapat mempengaruhi aspirasi kepemimpinan sangatlah penting, yaitu pemahaman bagaimana identifikasi organisasi dan orientasi komunal berinteraksi dan bagaimana cara berinteraksi satu sama lain.

Menurut Mintzberg (1979) dalam Duha (2016), terdapat lima komponen membentuk organisasi: inti operasi, puncak strategis, manajemen menegah, struktur teknologi, dan unit pendukung. Puncak strategis adalah orang yang bertanggung jawab atas keseluruhan tanggung jawab organisasi. Manajemen menengah menghubungkan perintah dari kepala untuk dieksekusi oleh bawahan dan informasi pendukung, serta teknostruktur.

Lau et al, (2019), mempelajari model pembelajaran organisasi kolektif untuk pengembangan organisasi. Penelitian ini membahas tentang masalah pembelajaran organisasi tradisional dan model pembelajaran organisasi baru. Saat ini, organisasi berfokus pada pembelajaran struktural yang memfasilitasi penciptaan pengetahuan formal dan informal.

Dalam pengembangan organisasi, diagnosis digunakan dengan sangat. Diagnosis organisasi, merupakan proses kolaborasi antara anggota organisasi dan konsultan pengembangan organisasi dalam mengumpulkan informasi yang bersangkutan, menganalisa, dan menggambarkan kesimpulan untuk perencanaan aksi dan intervensi. Jadi proses organisasi adalah kerjasama dalam mengumpulkan data dalam organisasi tersebut, sebagai langkah strategik kedepan dari oragnisasi (Jessica dan Rebecca, 2016).

Pengembangan organisasi dapat dianalisis melalui pendekatan intervensi technostruktural (French dan Bell, 1999). Pendekatan intervensi technostruktural juga dapat diterapkan di sekolah dalam mengidentifikasi tentang keterlibatan karyawan, metode-metode desain organisasi, kelompok, dan jenis pekerjaan di sekolah. Di sekolah, keberadaan struktur organisasi sangat penting karena dapat menunjukkan peran masing-masing dengan alur kerja yang jelas sehingga setiap personal memiliki tugas dan tanggung jawab masing-masing. Hal ini juga diterapkan di sekolah, intervensi dilakukan dengan mendesain kembali struktur organisasi sekolah yang dikaitkan dengan tugas dan tanggung jawab setiap elemen seperti pegawai sekolah. Ini dilakukan agar tidak terjadi tumpang tindih dalam pelaksanaan pekerjaan dan dapat membuat seluruh pegawai dapat menjalankan job descriptionnya secara personal (John, 2013). Struktur organisasi yang efektif dapat menentukan efektifitas dan kualitas kinerja serta achievement tujuan organisasi sekolah yang merupakan tujuan dari adanya pengembangan organisasi. 
Pengembangan organisasi bertujuan untuk membuat organisasi lebih terbuka dan lebih adaptif melalui peningkatan kemampuan dan potensi dalam rangka merencanakan perubahan yang berorientasi pada tindakan. Intervensi dalam organisasi pembelajaran diperlukan untuk membantu mengembangkan organisasi (Watare et al, 2007). Intervensi dalam pengembangan dimaksudkan untuk menetapkan cara-cara apakah yang patut dipergunakan untuk merencanakan perbaikan berdasarkan masalah yang ditemukan dalam proses diagnosa dan pemberian umpan balik. Intervensi berarti keikutsertaan klien dan konsultan bersama-sama merencanakan proses perbaikan berdasarkan atas masalah yang di temui dalam proses diagnosa organisasi (Gesimba, 2014). Tahap perencanaan intervensi harus diikuti dengan serangkaian konsep yang saling berhubungan satu sama lain yaitu adanya informasi yang benar dan bermanfaat, kebebasan memilih, dan keterikatan di dalam. Memperhatikan tiga kriteria diatas kita dapat menangkap bahwa proses intervensi itu memang sangat tergantung pada proses diagnosa. Dengan kata lain proses pengumpulan data akan banyak mewarnai kegiatan intervensi yang akan dijalankan.

Salah satu bentuk intervensi dalam pengembangan organisasi adalah adalah intervensi teknostruktural. Bentuk ini adalah sebuah model intervensi menggunakan pendekatan teknologi dan struktural dalam prosesnya (Siruri, 2019). Intervensi Teknostruktural menekankan pada peningkatan efektivitas organisasi dan pengembangan sumber daya manusia dengan berfokus pada teknologi dan struktur organisasi, sehingga diharapkan intervensi ini mampu meberikan dampak pembaruan dan memberikan efek yang lebih positif terhadap pengembangan organisasi.

Intervensi teknostruktural menawarkan intervensi untuk meningkatkan organisasi melalui transformasi dalam tugas, struktur, teknologi, sistem dan tujuan. Jenis intervensi ini sangat bergantung pada pendekatan berbasis deficit, yaitu gagasan utamanya adalah untuk memecahkan masalah. Menurut Cummings dan Worley (2005) pendekatan teknostruktural memfokuskan pada peningkatan teknologi organisasi (misalnya metode penugasan dan desain pekerjaan) dan struktur (misalnya pembagian kerja dan hirarki).

Intevensi teknostruktural di sekolah bertujuan untuk meningkatkan kualitas, metode dan interaksi sosial seluruh komponen sekolah. Teknologi dan struktur organisasi disajikan dalam intervensi teknostruktural yang berasal dari disiplin ilmu teknik, sosiologi, dan psikologi. Metode ini mencakup pendekatan kepala sekolah sebagai pemimpin dan karyawan di sekolah. Desain struktural berfokus pada kemampuan anggota yang dirancang dengan baik dari segi fungsional, unit mandiri dan struktur maktris. Desain akan lebih disederhanakan menjadi lebih integratif dan fleksibel. Lingkungan, teknologi dan kondisi organisasi merupakan faktor penentu struktur organiasi yang baik (Wang dan Colbert, 2011). Menurut Baskoro (2018) analisis intervensi teknostruktural memiliki wawasan yang luas dan pandangan kritis tentang bisnis dan merekomendasikan saran yang lebih strategis.

Berikut ini beberapa cara yang dapat dilakukan seorang kepala sekolah dalam mewujudkan intervensi technostruktural di sekolah yang di pimpinnya, yaitu :

\section{Work Design}

Program perubahan dalam kelompok kerja dipertimbangkan untuk mengembangkan dan mengintegrasikan sumber daya manusia ke arah yang konsisten dan strategis. Dalam pendekatan work design terdapat tiga teori yaitu,

a. The engineering approach : teori ini mengkaji tentang efisiensi cara kerja dari tradisi menjadi modern dan lebih efisien. Gaya kerja yang lebih simple dan efisien akan lebih memaksimalkan waktu dan tenaga kerja.

b. Motivational theories : teori ini melakukan pendekatan untuk meningkatkan motivasi pegawai. Sehingga pegawai mampu terus menjaga motivasinya dalam bekerja. Pendekatan personal sangat dibutuhkan dalam meningkatkan motivasi kinerja pegawai, seperti hubungan gaya kepemimpinan kepala sekolah yang situasional dengan seluruh elemen di madrasah. Kepala sekolah sebagai pemimpin harus mampu mendorong semangat kerja pegawai dengan cara melakukan pendekatan personal dan mengapresiasi prestasi yang telah dicapai oleh pegawai madrasah.

Menurut model Hackman dan Oldman, ada beberapa hal yang perlu diperkaya bagi seorang pegawai di sekolah yaitu:

1) Skill variety (Variasi keterampilan), yaitu dengan meningkatkan jumlah keterampilan yang dimiliki pegawai terkait dengan pekerjaannya di madrasah.

2) Task identity ( identitas tugas), sejauh mana pegawai di madrasah melakukan tugasnya. Tugas yang direncanakan harus disusun melalui rancangan yang detail dan terukur. Seperti perancangan proses pembelajaran selama satu semester.

3) Task significance (signifikansi tugas), setiap pegawai di madrasah dapat mengevaluasi tugas yang telah dikerjakan. Dalam proses pengayaan pekerjaan tentunya juga akan menghadapi hambatan-hambatan. Seperti masalah teknis, yaitu yang berkaitan dengan sistem teknologi informasi, sistem personil yaitu tingkat fleksibilitas dalam mengerjakan tugas-tugas pegawai di madrasah, serta sistem kontrol yang dilakukan oleh Kepala Sekolah seperti laporan pembelajaran maupun laporan anggaran sekolah. Sistem pengawasan juga 
diperlukan untuk mengevaluasi kinerja, seperti Kepala Sekolah mengevaluasi kendala-kendala terkait pelaksanaan pembelajaran dan memberikan solusi seperti mengadakan pelatihan, kompensasi dan supervisi.

2. Sociotechnical systems methods : teknik pengembangaan kemampuan bersosial. Apabila pegawai mampu berkerjasama dengan baik, maka sekolah akan mendapatkan keuntungan dalam hal efisiensi pegawai. Pendekatan ini terdiri dari dua bagian yaitu bagian sosial, termasuk di dalamnya adalah performa pekerja dan hubungan diantara pegawai di sekolah, dan bagian teknik berupa peralatan, alat, serta teknik pembelajaran dalam melakukan performansi.

\section{SIMPULAN}

Pelaksanaan diagnosing organisasi melalui intervensi technostruktural di sekolah bertujuan untuk meningkatkan kualitas dan efisiensi kinerja setiap pegawai yang ada disekolah. Dalam pelaksanaan organisasi, peningkatan kinerja penentu perubahan apa yang akan dihasilkan sehingga setiap pegawai harus mengetahui peran, tugas dan tanggungjawabnya masingmasing.

Ada beberapa cara yang dapat dilakukan pada pendekatan ini, diantaranya adalah,

\section{Self managed work teams}

Cara yang dilakukan adalah dengan mengatur diri sendiri dalam kinerja di sekolah, desain kerja ini terdiri dari anggota pelaksana tugas-tugas yang saling terkait. Kepala sekolah mengendalikan karyawan untuk mampu bertanggungjawab akan tugas dan membuat keputusan tentang tugas tugas yang dilakukan.

\section{Team task design}

Adalah tanggung jawab untuk tugas-tugas tertentu, konsekuensi dari seluruh pegawai disekolah atas apa yang telah dikerjakan. Ketika pegawai berhasil mengerjakan tugasnya, maka mereka akan melihat bahwa kontribusi mereka nyata dalam mengembangkan dan memajukan organisasi.

\section{DAFTAR PUSTAKA}

Abdullah, A.G.K., Ling, Y.L., Sufi, S.B. 2018. Principal Transformational Leadership and Teachers Motivation. Asian Education Studies; Vol. 3, No. 1.

Baskoro, Agung. 2018. Technostructural Intervention of the Tax Ombudsman Unit in Indonesia: A study on taxation oversight committee. International Institue of Social Studies. The Hague, The Netherlands.

Boyinbode OK \& Ainyede RO. 2008. Mobile Learning: an Application of Mobile and Wireless Technologies in Nigerian Learning System.
6International Journal of Computer Science and Network Security, 8(11):386-392.

Cresweel, John, W. 2015. Penelitian Kualitatif Dan Desain Riset. International Journal of Physiology, 3(1), 674.

Cummings, T.G. \& Worley, C.G. (2005). Organizational Development and Change (8th Edition). Mason, $\mathrm{OH}$ : Thomson South-Western.

Duha, Timotius. 2016. Perilaku Organisasi. Yogyakarta: Deepublish.

French, Wendell L. Dan Bell, Cecil H. Jr. 1999. Organization development : behaviora science interventions for organization limprovement. New Jersey: Prentice hall.

Gesimba, Dr. Paul Omato. 2014. “Organization Development Interventions on Procurement Practice and Budgetary Control at Nakuru Municipal Council in Kenya, Africa". Vol. 5 No.4.

HR Intelligence Report. 2008. Organizational Diagnostic Models A Review \& Synthesis. Artikel, Sacramenta California

Lau Kung Wong, Lee Pui Yuen, Chung Yan Yi. 2019. A Collective Organizational Learning Model For Organizational Developmen. Emerald Insight; Leadership \& Organization Development Journal Vol. 40 No. 1.

Lexy J. Moleong, D. M. . 2017. Metodologi Penelitian Kualitatif. PT.Remaja Rosdakarya

Mackenzie, Jessica dan Gordon, Rebecca. 2016. Studi Pengembangan Organisasi. Jakarta : Bappenas.

Munandar, A.S. 2014. Psikologi industri dan organisasi. Jakarta: Penerbit Universitas Indonesia (UI-Press)

Rahmi, Sri. 2014. Kepemimpinan Transformasional dan Budaya Organisasi. Bogor: Mitra Wacana Media.

Robbins, Stephen P. \& Judge, Timothy. 2008. Perilaku Organisasi. Jakarta: Salemba Empat.

Roland L. Sullivan William J. Rothwell Mary Jane B. Balasi (2013). "Organizatioan development (OD) and change management (CM): whole system transformation", Development and Learning in Organizations, Vol 27 Iss 6 pp. 18-23.

Siruri, Marwa Moses. 2019. Technostructural Interventions and Performance of Commercial Banks in Kenya. A Thesis Submitted to the School of Business in Partial Fulfillment of the Requirement for the Award of the Degree of Doctor of Philosophy in Business Administration (Human Resource Management Option) of Kenyatta University.

Theodore, John .2013. "Organizational Development Interventions In Learning Organizations." International Journal of Management \& Information Systems (Online) 17.1 (2013): 65.

Usman, H. (2008). Peranan dan Fungsi Kepala Sekolah / Madrasah. Jurnal PTK DIKMEN,Vol. 3 No. 1. 
Marjanis, Hendri Yazid, Rusdinal dan Nurhizrah Gistituati, Penerapan Diagnosing Organisasi Melalui Intervensi Technostruktural: Studi Literatur

Wang, G., Courtrigh, S.H., Colbert, A.E. 2011. Transformational Leadership and Performance Across Criteria and Levels: A Meta-Analytic Review of 25 Years of Research. Journal Group and Organization Management, Vol 36 No 2.

Watare, A., Njuguna R, Maina S. 2007. Organization Development Interventions and Performance of Airtel Kenya. Kenya: Kenyatta University. 